Energy Research Journal 1 (1): 42-46, 2010

ISSN 1949-0151

(C) 2010 Science Publications

\title{
Applied a Closed-Loop Oscillating Heat-Pipe Heat Exchanger to Increasing Oil Yield in Pyrolysis Process
}

\author{
${ }^{1}$ N. Panyoyai, ${ }^{1}$ T. Wongsiriamnuay and ${ }^{2}$ S. Sangsrichan \\ ${ }^{1}$ Department of Agricultural and Food Engineering, \\ Faculty of Engineering and Agricultural Industry, \\ ${ }^{2}$ Department of Chemistry, Faculty of Science, \\ Maejo University, Chiang Mai 50290, Thailand
}

\begin{abstract}
Problem statement: A Closed-Loop Oscillating Heat-Pipe (CLOHP) heat exchanger was a heat exchanger with one of the most promising conductivity capacities because of its higher cooling and condensing potential. Therefore, the aims of this study were to design and fabricate a CLOHP to be applied to increasing oil yield in the pyrolysis process. Approach: Two types of oscillating heatpipe arrangements-parallel and perpendicular to the gas flow direction-were compared with a conventional water-to-air condenser or glass-type heat exchanger. The oscillating heat-pipe was made of four sets of copper tubes working at $90^{\circ}$ from the horizontal plane, with an inner diameter of $2.03 \mathrm{~mm}$ and a total length of $18 \mathrm{~m}$. The number of turns was 15 . The lengths of the evaporator and condenser sections were 50 and $100 \mathrm{~mm}$ in total, respectively. R123 was used as a working fluid, 50\% by total volume. In the experiment, an air velocity of $0.4 \mathrm{~m} \mathrm{sec}^{-1}$ was applied to the condenser section. $100 \mathrm{~g}$ of $5 \times 5 \mathrm{~mm}$ pieces of motorcycle tire inner tubes were burned in a pyrolysis furnace of $500^{\circ} \mathrm{C}$, having a heat-rate of $10^{\circ} \mathrm{C} \mathrm{min}$. . Result: The results showed that a CLOHP parallel to the gas flow direction was more effective, resulting in $39.08 \mathrm{~g}$ crude oil from the hot gas in the pyrolysis process and a maximum heat flux of $1,181.53 \mathrm{~W} \mathrm{~m}^{-2}$. Conclusion: This study suggested that to improve the performance of a pyrolysis process which uses scrap motorcycle tire waste as a heating agent, a CLOHP should be placed in parallel to the gas flow line.
\end{abstract}

Key words: Pyrolysis, oscillating heat-pipe, heat exchangers, scrap motorcycle tire

\section{INTRODUCTION}

Heat-pipe heat exchangers have a high heat transfer rate and thermal performance (Akachi et al., 1996). In this study, capillary copper tubes were used and filled with working fluid. The diameter of the capillary tubes used to make the oscillating heat pipe did not exceed the critical diameter in the equation below (Maezawa et al., 1996):

$D_{i, \text { crit }}=\sqrt[2]{\frac{\sigma}{\rho_{\mathrm{L}} \mathrm{g}}}$

Where:

$\mathrm{D}_{\mathrm{i}, \text { crit }}=$ Critical diameter $(\mathrm{m})$

$\sigma=$ Surface tension $\left(\mathrm{N} \mathrm{m}^{-1}\right)$

$\rho_{\mathrm{L}} \quad=$ Density of saturated liquid $\left(\mathrm{kg} \mathrm{m}^{-3}\right)$

$\mathrm{g} \quad=$ Acceleration due to gravity $\left(\mathrm{m} \mathrm{sec}^{-2}\right)$
Closed-Loop Oscillating Heat-Pipes (CLOHP) are made from a long copper capillary tube, bent into an undulating tube and connected at each end into a closed-loop form; no internal wick structure is required. Three types of CLOHP structures are shown in Fig. 1 (Charoensawan et al., 2003).

Heat transfer occurs due to a strongly oscillating pressure wave. The working fluid, which is in liquid plug and vapor bubble form, will evaporate, expand and move toward the cooler section. Then vapor bubbles will condense, collapse and release heat to the heat sink.
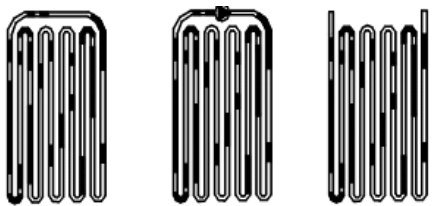

Fig. 1: Three types of oscillating heat pipes

Corresponding Author: N. Panyoyai, Department of Agricultural and Food Engineering, Faculty of Engineering and Agricultural Industry, Maejo University, Chiang Mai 50290, Thailand Tel: +66 5387 5869-71 Fax: +66 53878113 
This evaporation and collapsing of vapor bubbles is the main mechanism by which the working fluid can circulate and continuously transfer the heat in a cycle (Soponpongpipat et al., 2006). Heat transfer results from oscillation of the working fluid circulating in only one direction, the axial direction, of the tube. From the tire pyrolysis process, condensation of hot gas can ultimately be turned into crude oil that can be used as engine fuel (Aylon et al., 2007; Murugan et al., 2008). The condensable temperature can achieve a maximum yield of liquid fuel from tire pyrolysis (Williams and Brindle, 2003). The heat exchange system affects liquid yields in the tire pyrolysis process (Berrueco et al., 2005). In this study, CLOHP have been applied to a condenser system for scrap tire pyrolysis in a fixed bed reactor. Pyrolysis gases are passed directly to a designed heat exchanger system for condensation. The aim of the work was to obtain condensation of liquid yield with different types of condensation equipment. The particular selective condensation equipment is mainly dependent on the dew point of the components of the liquid, which is closely linked to the boiling point of that compound; so it becomes apparent that selective condensation would prove useful for the condensation of pyrolysis oil. The temperature-selective condensation is analogous to the separation of the components of oils via distillation. However, temperature-selective condensation differs from distillation in that fractionation is achieved by cooling gaseous products to liquids, rather than in the case of distillation where oil is transformed from its liquid state to a vaporous state to afford separation. The parameters examined were the types of condenser systems.

\section{MATERIALS AND METHODS}

Airflow velocity was calculated by means of comparison with water flow rate through a heat exchanger which was made of glass. It could be assumed that the heat transfer rate of a glass-type heat exchanger was equal to that of a CLOHP heat exchanger. The mass flow rate of air was obtained from following equation (Faghri, 1995):

$\mathrm{Q}=\dot{\mathrm{m}} \mathrm{C}_{\mathrm{p}}(\Delta \mathrm{T})$

Where:

$\mathrm{Q}=$ Heat transfer rate $\left(\mathrm{kJ} \mathrm{sec}^{-1}\right)$

$\dot{\mathrm{m}}=$ Mass flow rate $\left(\mathrm{kg} \mathrm{sec}^{-1}\right)$

$\mathrm{C}_{\mathrm{p}}=$ Specific heat $\left(\mathrm{kJ} \mathrm{kg}^{-1} \mathrm{C}^{-1}\right)$

$\Delta \mathrm{T}=$ Temperature difference $\left({ }^{\circ} \mathrm{C}\right)$

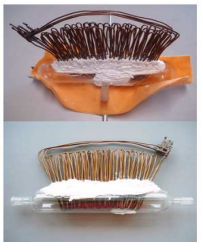

Fig. 2: The two types of oscillating heat-pipes arranged parallel and perpendicular to the gas flow direction

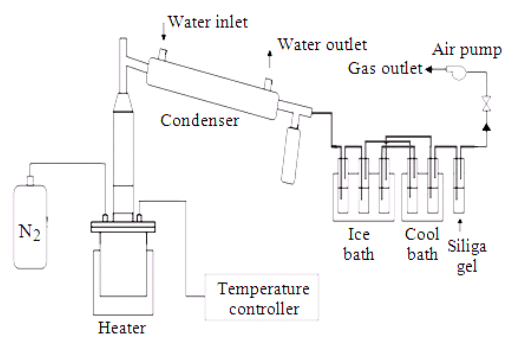

Fig. 3: Experimental setup of pyrolysis process with condenser or glass-type heat exchanger

A fan propeller velocity was obtained from the equation to specify airflow velocity for a CLOHP heat exchanger experiment which would remain the same value throughout the test:

$\dot{\mathrm{V}}=\mathrm{AV}$

Where:

$\dot{\mathrm{V}}=$ Volume flow rate $\left(\mathrm{m}^{3} \mathrm{sec}^{-1}\right)$

$\mathrm{A}=$ Cross sectional area $\left(\mathrm{m}^{2}\right)$

$\mathrm{v}=\operatorname{Velocity}\left(\mathrm{m} \mathrm{sec}^{-1}\right)$

Design and fabrication of closed-loop oscillating heat-pipe heat exchanger.

Four sets of the closed-loop oscillating heat-pipe, arranged parallel and perpendicular to the gas flow direction, were made of copper tubing with an inner diameter of $2.03 \mathrm{~mm}$. The evaporator and condenser section lengths were 50 and $100 \mathrm{~mm}$, respectively (Charoensawan and Terdtoon, 2008), with a total length of $18 \mathrm{~m}$. There were 15 turns. The two types of oscillating heat-pipe arrangements are shown in Fig. 2. Furthermore, reinforced instruments for the oscillating heat-pipe sets were cooling sets consisting of two fans, $10 \mathrm{~cm}$ in size, fixed on galvanized iron with a dimension of $30 \times 30 \times 25 \mathrm{~cm}$. They were set up to cover the oscillating heat-pipe sets in order to cool the pipes.

Experimental procedure of burning by pyrolysis process with glass-type heat exchanger and show in Fig. 3:

- Scraps used consisted of pieces of inner tubes of motorcycle tires, each approximately $5 \times 5 \mathrm{~mm}$ and 
in dry condition; around $100 \mathrm{~g}$ were burned in a pyrolysis furnace

- Water and crushed ice were filled in the container to cooling condense gas

- The instrument sets of the pyrolysis process were connected to the glass-type heat exchanger

- Aluminum tape and paraffin were wrapped at connections to prevent leaking of gas from system

- The thermocouple was set to data logger to measure temperature at any point

- A rubber tube, joined to a water tap, was connected to the glass-type heat exchanger

- Water flowed into the glass-type heat exchanger at an adjusted flow rate of $0.6 \mathrm{~L} \mathrm{~min}^{-1}$

- Nitrogen was adjusted at $100 \mathrm{~mL} \mathrm{~min}^{-1}$ into the pyrolysis furnace to evacuate the system

- Nitrogen was pumped from the system in order to prevent excessively high pressure which could cause instrument damage

- The heater was turned on to supply heat for burning motorcycle tire inner tube pieces in the pyrolysis furnace

- All data were recorded

Experimental procedure of burning by pyrolysis process with CLOHP heat exchanger and show in Fig. 4:

- $100 \mathrm{~g}$ of $5 \times 5 \mathrm{~mm}$ pieces of motorcycle tire inner tubes were burned in a pyrolysis furnace

- Water and crushed ice were filled in the container to cooling condense gas

- The instrument sets of the pyrolysis process were connected to the CLOHP heat exchanger (replacing the glass-type heat exchanger) and arranged parallel and perpendicular to the gas flow direction

- The cooling sets consisted of two 4-in fans which were set up to cover the oscillating heat-pipe sets to cool the system

- Paraffin and aluminum tape were applied and wrapped at all connections to prevent gas leaking from the system

- The thermocouple was set to data logger to measure temperature at any point

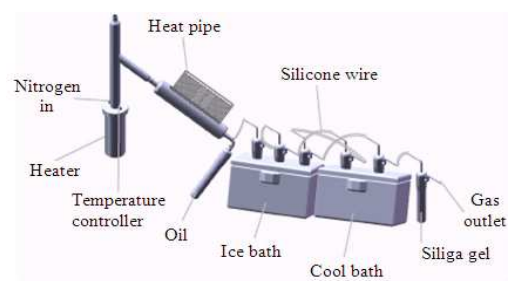

Fig. 4: Experimental setup of the pyrolysis process with a Closed-Loop Oscillating Heat-Pipe (CLOHP) heat exchanger
- A rubber tube, joined to a water tap, was connected to a CLOHP heat exchanger

- Water flowed was adjusted flow rate of $0.6 \mathrm{~L} \mathrm{~min}^{-1}$

- Nitrogen was adjusted at $100 \mathrm{~mL} \mathrm{~min}^{-1}$ into the pyrolysis furnace to evacuate the system

- Nitrogen was pumped from the system in order to prevent excessively high pressure which could cause instrument damage

- Heater was turned on to supply heat for burning motorcycle tire inner tube pieces in the pyrolysis furnace

- All data were recorded and compared with the data from pasted obtained

\section{RESULTS}

Calculations indicated that airflow velocity through the heat exchanger was $0.4 \mathrm{~m} \mathrm{sec}^{-1}$. This was applied to specify airflow velocity for the CLOHP heat exchanger experiment, in which the DC power supply was adjusted to approach calculated air flow velocity.

Experimental results of pyrolysis process with condenser or glass-type heat exchanger: During the experimental pyrolysis process with the glass-type heat exchanger, water inlet and outlet temperatures were 26 and $27^{\circ} \mathrm{C}$, respectively, for the $500^{\circ} \mathrm{C}$ pyrolysis furnace temperature. The product obtained from the heating process was analyzed by means of approximate analysis. Experiments were done in triplicate to determine average values, which are shown in Table 1 and 2.

Table 1:Average water inlet and outlet temperatures of a glass-type heat exchanger

\begin{tabular}{ll}
\hline Temperature measurement location & Temperature $\left({ }^{\circ} \mathrm{C}\right)$ \\
\hline Inlet water & 26.00 \\
Outlet water & 27.00 \\
\hline
\end{tabular}

Table 2: Experimental results of the pyrolysis process with a glasstype heat exchanger

\begin{tabular}{ll}
\hline Product from burning process & Percentage by mass \\
\hline Crude oil & 34.17
\end{tabular}

Residual gas from condensate oil compound with nitrogen 11.60

Table 3: Average airflow inlet and outlet temperatures of a CLOHP heat exchanger arranged parallel to the gas flow direction

Temperature measurement location $\quad$ Temperature $\left({ }^{\circ} \mathrm{C}\right)$

Inlet airflow 29.50

$\begin{array}{ll}\text { Outlet airflow } & 32.00\end{array}$

Table 4: Experimental results of the pyrolysis process with a CLOHP heat exchanger arranged parallel to the gas flow direction

\begin{tabular}{ll}
\hline Product from burning process & Percentage by mass \\
\hline Crude oil & 39.10
\end{tabular}

\begin{tabular}{ll} 
Residual gas from condensed oil compound with nitrogen & 12.74 \\
\hline
\end{tabular}

Table 5: Average airflow inlet and outlet temperatures of a CLOHP heat exchanger arranged perpendicular to the gas flow direction

Temperature measurement location $\quad$ Temperature $\left({ }^{\circ} \mathrm{C}\right)$

Inlet airflow 31.50

Outlet airflow $\quad 33.50$

Table 6: Experimental results of the pyrolysis process with a CLOHP heat exchanger arranged perpendicular to the gas flow direction

\begin{tabular}{ll}
\hline Product from burning process & Percentage by mass \\
\hline Crude oil & 38.13
\end{tabular}

Residual gas from condensed oil compound with nitrogen 12.72 
Experimental results of the pyrolysis process with a CLOHP heat exchanger arranged parallel to the gas flow direction: The pyrolysis process with a CLOHP heat exchanger, which was arranged parallel to the gas flow direction, obtained results as shown in Table 3 and 4 .

Experimental results of the pyrolysis process with a CLOHP heat exchanger arranged perpendicular to the gas flow direction: The pyrolysis process with a CLOHP heat exchanger, which was arranged perpendicular to the gas flow direction, obtained results as shown in Table 5 and 6 . Obtained product quantity difference between the pyrolysis processes using glass-type and closed-loop oscillating heat-pipe heat exchangers.

\section{DISCUSSION}

The pyrolysis processes with glass-type and closed-loop oscillating heat-pipe heat exchangers were experimentally compared, as shown in Fig. 6 and 7, respectively, for their obtained product quantity of crude oil and condensed oil compound with nitrogen. It was found that the quantity of crude oil and condensed oil compound with nitrogen obtained from the pyrolysis process with the CLOHP heat exchanger was higher than that with the glass-type heat exchanger. Pyrolysis processes with the CLOHP heat exchanger experiment arranged both parallel and perpendicular to the gas flow direction were compared. It was found that the quantity of condensate from hot gas, which ultimately turned into crude oil (from motorcycle tire inner tubes burned by the pyrolysis process) from a CLOHP heat exchanger arranged parallel to the gas flow direction was higher than that arranged perpendicular to the gas flow direction.

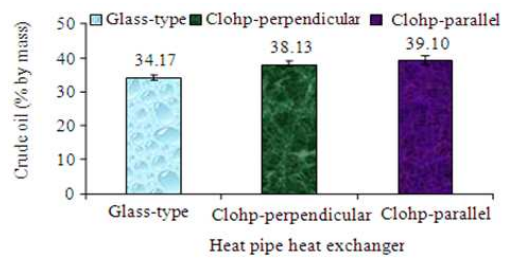

Fig. 5: Comparison of crude oil quantity obtained from the burning process at $500^{\circ} \mathrm{C}$ pyrolysis furnace temperature within $30 \mathrm{~min}$

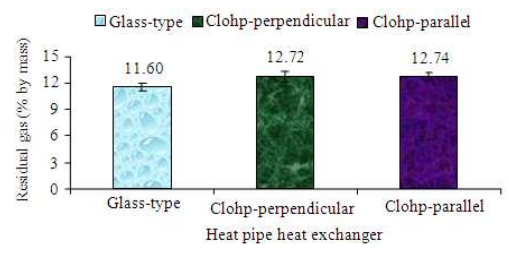

Fig. 6: Comparison of residual gas quantity from condensed oil compound with nitrogen obtained from burning process at $500^{\circ} \mathrm{C}$ pyrolysis furnace temperature within $30 \mathrm{~min}$
From the bar chart in Fig. 5, illustrating the comparison of crude oil quantity, it can be seen that hot gas contacting the heat exchanger area within a short period resulted in a lower condensation of hot gas than expected. However, the resulting quantity obtained from a CLOHP system tended to be higher than that from a glass-type heat exchanger. Oven reactor temperature was $500^{\circ} \mathrm{C}$, which is the optimum temperature to obtain a high yield of liquid from tire pyrolysis but when the experimental equipment was changed from a glass condenser to a heat-pipe heat exchanger, which has a higher heat transfer rate, there was a higher liquid product yield from tire pyrolysis.

From the bar chart in Fig. 6, illustrating the comparison of residual gas quantity from condensed oil compound with nitrogen, it can be seen that condensation of hot gas from the pyrolysis process with the CLOHP heat exchanger arranged parallel to the gas flow direction produced the highest quantity. Therefore, it had a higher tendency to obtain crude oil due to the higher resulting residual gas. Calculation results of heat exchanger heat transfer rate.

From the pyrolysis process with the glass-type and the CLOHP heat exchanger experiment, the resulting heat transfer rates were $41.63,83.30$ and $104.21 \mathrm{~W}$ for the glass-type heat exchanger and the CLOHP heat exchanger arranged perpendicular and parallel to the gas flow direction, respectively. The comparison of the three different types of heat exchanger heat transfer rates found that the pyrolysis process with the CLOHP heat exchanger obtained a higher heat transfer rate than that from the glass-type heat exchanger, as shown in Fig. 7.

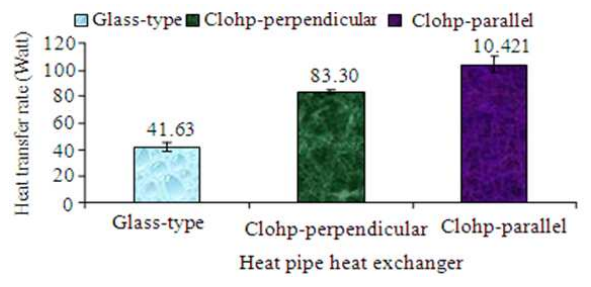

Fig. 7: Heat transfer rate of each type of heat exchanger

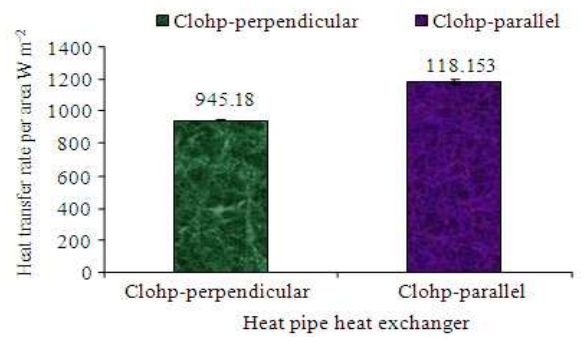

Fig. 8: Heat transfer rate per area of the CLOHP heat exchanger 
From the bar chart in Fig. 7 illustrating the heat exchanger heat transfer rate, it can be seen that the heat transfer rate of the CLOHP heat exchanger was higher than that from the glass-type heat exchanger because R123 was used as a working fluid within the heat pipes, its better ability to transfer heat than water caused a heat transfer rate higher than a glass-type heat exchanger.

Calculation results of heat transfer rate per area of the CLOHP heat exchanger: The CLOHP heat exchanger experiment was arranged both parallel and perpendicular to the gas flow direction; these two heat transfer rates were 945.18 and $1,181.53 \mathrm{~W} \mathrm{~m}^{-2}$, respectively. It was also found that heat transfer rate per area of the CLOHP heat exchanger experiment arranged perpendicular to the gas flow direction was higher than that arranged parallel to the gas flow direction, as shown in Fig. 8.

From the bar chart in Fig. 8 illustrating the heat transfer rate per area of the CLOHP heat exchanger, it can be seen that the parallel arrangement to the gas flow direction obtained more heat than the other arrangement, due to its contacted with the heat exchanger area throughout the tube. Therefore the heat transfer rate per area of the CLOHP heat exchanger arranged parallel to the gas flow direction was higher than that arranged perpendicular to the gas flow direction.

\section{CONCLUSION}

From approximate analysis, it was found that the quantity of condensation of hot gas, which was ultimately turned into crude oil, from the inner tubes of motorcycle tires burned by the pyrolysis process with the CLOHP heat exchanger, was higher than that with the glass-type heat exchanger.

The oscillating heat-pipe arrangement affected hot gas condensation during the pyrolysis process. The crude oil quantity from hot gas condensation with the CLOHP heat exchanger arranged parallel to the gas flow direction was higher than that arranged perpendicular to the gas flow direction.

The heat transfer rate of a glass-type heat exchanger, in which water was used as the working fluid, was $41.63 \mathrm{~W}$. The heat transfer rate and heat transfer rate per area of a CLOHP heat exchanger arranged parallel to the gas flow direction were $104.21 \mathrm{~W}$ and $1,181.53 \mathrm{Wm}^{-2}$, respectively. The heat transfer rate and heat transfer rate per area of a CLOHP heat exchanger arranged perpendicular to the gas flow direction were $83.30 \mathrm{~W}$ and $945.18 \mathrm{Wm}^{-2}$, respectively. The best heat transfer rate of heat exchangers was 104.21 W in the CLOHP heat exchanger. The best heat transfer rate per area of heat exchangers was $1,181.53$ $\mathrm{W} \mathrm{m}{ }^{-2}$ of the CLOHP heat exchanger.

\section{ACKNOWLEDGEMENT}

This research was conducted using research funds from the Faculty of Engineering and Agro-Industry, the Faculty of Science, Maejo University and the Energy Fund of the Thailand Ministry of Energy.

\section{REFERENCES}

Akachi, H., F. Polasek and P. Stulc, 1996. Pulsating heat pipes. Proceeding of the 5th International Symposium on Heat Pipe, Melbourne, Australia, pp: 208-217.

Aylon, E., R. Murillo, A. Fernandez-Colino, A. Aranda and T. Garcia et al., 2007. Emissions from the combustion of gas-phase products at type pyrolysis. J. Anal. Applied Pyrol., 79: 210-214.

Berrueco, C., E. Esperanza, J. Mastral and J. Ceamanos, 2005. Pyrolysis of waste tyres in an atmospheric static-bed batch reactor: Analysis of the gases obtained. J. Anal. Applied Pyrol., 74: 245-253.

Charoensawan, P. and P. Terdtoon, 2008. Thermal performance of horizontal closed-loop oscillating heat pipe. Applied Therm. Eng., 28: 460-466.

Charoensawan, P., P. Terdtoon, P. Tantakom and P. Ingsuwan, 2003. Effect of evaporator section lengths, number of turns and working fluid on internal flow patterns of a vertical closed-loop oscillating heat pipe. Proceeding of the 7th International Symposium on Heat Pipe, Oct.12-16, Jeju, Korea, pp: 260-267.

Faghri, A., 1995. Heat Pipe Science and Technology. Taylor and Francis. Washington DC, USA, pp: 874.

Maezawa, S., K.Y. Gi, A. Minamisawa and H. Akachi, 1996. Thermal performance of capillary tube thermosyphon. Proceedings of the 9th International Heat Pipe Conference, Albuquerque NM., USA., pp: 791.

Murugan, S., M.C. Ramaswamy and G. Nagarajan, 2008. The use of tyre pyrolysis oil in diesel engines. Waste Manage., 28: 2743-2749.

Soponpongpipat, N., P. Sakulchangsatjatai, M. Sornseub and P. Terdtoon, 2006. Time response model of operational mode of closed-loop oscillating heat pipe at normal operation. Proceeding of the 8th International Symposium on Heat Pipe, Sept. 2427, Kumamoto, Japan, pp: 291-296.

Williams, P.T. and A.J. Brindle, 2003. Temperature selective condensation of tyre pyrolysis oils to maximize the recovery of single ring aromatic compounds. Fuel, 82: 1023-1031. 